\title{
René Girard and Mimetic Desire
}

René Girard is famous for his mimetic theory of desire across different fields of scholarship. My aim is to scrutinize his theory from a philosophical point of view. His basic idea and theory appear to be deceptively simple. The theory has two parts, namely, the main thesis and its implications. The thesis says, a desiring subject always copies her desires from a model, or it has a relevant source. Desire is triangular or based on a three-place relation: subject - model object. Next the main implication: subjects are anxious and hate each other because their desires are not properly recognized as their own. How could they be so recognized, they are copies and copies always are less valuable than the original. Paradoxically, no original exists because all models are desires and all desires are copies. I analyze and criticize Girard by showing how complex and unintuitive his theory actually is. I pay attention to the genesis of anxiety. I develop a sketch of an alternative view in terms of scripts of desire on the social stage.

\section{Girard on Desire}

René Girard says all desires are mimetic, or copied from some identifiable sources. ${ }^{1}$ His first and, as it seems, foundational example is Don Quixote of La Mancha who read too many historical romances and now wants to be a wandering knight. Of course, he recreates himself as fiction and therefore this is him as fiction in fiction, which is to say that first his readers speak about him in oratio obliqua and then he himself is driven to do the same. When we speak of him we refer to him via the fictional narrative created by Cervantes. When Don Quixote speaks about himself he refers to himself via the fiction he has

1 See R. Girard, Deceit, Desire, and the Novel: Self and Other in Literary Structure. Tr. Y. Freccero. Baltimore: John Hopkins University Press, 1965. This theory is evidently too simple to be psychologically valid. We sometimes copy desires but we also modify and reject them. I may not desire X simply because you desire X. My desires may represent other subjects' desires but to say they are copies is an oversimplification. However, from an analytical point of view, the simple view is fine. Girard's scholarly output is large but I focus only on his basic thesis. We cannot benefit from extensive empirical considerations here. They may lead us towards the ideas presented in J.D. Holden, Second that Emotion. Amherst, N.Y.: Prometheus Books, 2012; and K. Greenfield, The Myth of Choice. New Haven: Yale University Press, 2011. 
read, say, when he compares himself with the mythical and fictional heroes of the past. Girard says his character Don Q now is mimetic in nature, or a repetition or a copy of those knights that he finds on the pages of the novels he read. Girard says desires - all desires - are mimetic and his audience has listened. ${ }^{2}$ They have copied Girard's thesis. Anyway, we should ask what Girard means by his rather grandiose hypothesis.

It is of course possible that the man from La Mancha is the innocent victim of the following logical blunder, namely, he thinks he wants to be a wandering knight and believes that such a desire is satisfiable. The intentional object is, obviously, "wandering knight," so that "I am a wandering knight" is a proposition whose truth gratifies him. This is not so, as one can easily see, for instance, he fails to perform great deeds. Of course, once he has convinced himself that he indeed is a wandering knight he starts wandering around seeking for heroic opportunities. He made himself what he is now, a fictional character, but next he must write the narrative of his own adventures and this is what he is going to do. When you read the legend of Don Q you learn that to be a knight is what our man wants de dicto; thus, he lives like a wandering knight, from one imagined heroic deed to another doing good and punishing the bad. What he says is that he wants to share in the virtues of those immortal knights. He has not really copied the objects of desire, rather he has copied the essential desire itself, and then these objects constitute his new self-image. Fictional desires make a fictional self, of course, like Don Q a wandering knight. In this sense, it is the desire itself he wants, not some specific and special intentional objects, like rescuing young ladies. Or, we can say that he directly wants the desire and indirectly the heroic exploits. He always is happy with the overall scheme, or the grand desire itself, although his exploits never make him happy or satisfied. The noble knight attacks windmills that he thinks are hostile monsters, and that hurts.

He wants to be a wandering knight, which now is his new identity. We can emphasize three points here. First, what he imagines, his heroic adventures, follow from his desirable and desired new identity. In this sense "wandering knight" is what I call a desire frame, which is not an object as such, independently of the heroic deeds. He needs to save fair maidens only because he wants to be a wandering knight who necessarily rescues them; it is all based on this one grand desire, or desire frame, that determines his needs and deeds. The concept of need is not instrumental but constitutive in this context because he does not say "I want to save her" but "This is what a wandering knight does:

2 On mimesis, see A. Melberg, Theories of Mimesis. Cambridge: Cambridge University Press, 1995. 
I as a knight save maidens, she is a maiden, and therefore I save her." Second, Don $\mathrm{Q}$ as a wandering knight lives through a grand desire that he shares with his fellow fictional characters, the greatest of the hoary great knights. Third, Don Q enjoys it all, or he is as if immersed in the feeling of knightly virtue, the excitement of adventure, and the sense of power and capability etc. The key term here is feeling, or an emotive state without its fixed object or even descriptive sense. It is the feeling of being of a correct type of agent, and this feeling is good. It may be called pride but as well humility or any of the other relevant emotively charged states of mind. In sum: What do we have here? Don Q lives through a grand desire that works as a desire frame determining the actions that constitute his knightly identity at the same time sharing the great, proud feeling of being a knight. Accordingly, it is highly misleading to say that he wants to be a knight in the sense that "to be a knight" form the de dicto intentional object of a specific desire. Such a desire can be satisfied by the person becoming a knight, but Don Q does not want to become a knight or even to be a knight in this sense; what he wants is to live through the desire and enjoy it. In this sense, he desires the relevant desire. What is this desire? It is being what one already is. According to the propositional attitude theory of desire, this is impossible. You cannot desire, in the propositional sense, what you already have. ${ }^{3}$ You may love it, as Thomas Hobbes says, but what you have you cannot figure as the intentional object of a given desire. Desire in this sense requires that you figure out a new possible world where your desire can be satisfied. But Don Q does not only love what he is and what he does; on the contrary, he wants to do what he does and what, fictionally, he already is. In this sense, he enjoys his desire and in this sense he desires his satisfied desire, which therefore cannot have an intentional object and therefore cannot be a propositional attitude. He desires his desire; he desires to be a wandering knight, which in itself is a desire. Then his subsequent actions are based on his identity and motivated by it. Not all actions require propositional desires in their background.

The greatest of ideas are often simple but the simplest of ideas may be deceptive because simplicity does not guarantee the truth or originality of the idea. René Girard argues that desires are mimetic and his large audience tends to agree: "there is an irresistible impulse to desire what Others desire, in other words, to imitate the desires of others."4 This is empirical psychological point. The logically stronger idea follows: all desires are copies. These two theses are mutually independent and their relationship remains obscure to the

3 See the idea of f-desire, Chapter 1.

4 Girard, 1965, p. 12. Thorstein Veblen figured this out already in 1899 in his classic The Theory of the Leisure Class. New York: Dover, 1899/1964. 
end. What Girard says is that I desire things but such a mental state or episode cannot be described by means of a two-place relation; we need a third variable and consequently a three-place relation, or as he sees it, a triangle. I do not only desire something but I desire it on the basis of a relevant model that I copy. Girard seems to say that such a model is provided by other people whom we witness and from whom we adopt what we desire, when we desire. In this way, I desire X because of a model provided by other people. In other words, I know what they desire and therefore I desire it as well.

Now, I ask only one question: How should we understand Girard's point that desire is a triangle in the sense that "I desire X ..." must be completed by mentioning the source of this desire, or a model, that I copy when I desire. ${ }^{5} \mathrm{We}$ know that $X$ has its source, or a model that I copy. This is to say that my desire is not autonomous but, on the contrary, derivative. Are all desires derivative in this sense? Perhaps Girard should say he is interested in only those desires that are derivative? I can find no simple answer in Girard's own writings. They tend to be heuristic rather than analytical, suggestive rather than convincing, and literary rather than discursive. He is more like an inventor than an architect of ideas, and a preacher rather than a teacher. Here I approach his writings as if his grand vision of desire were a theory, however impolite that may be. However, it is clear that the mimetic theory is interesting because it postulates triangular desires and, thus, we should focus on it.

Let us say all desires are triangular; if we say some are and some are not we no longer have a triangular theory of desire. On the contrary, we have a twoplace theory that is supplemented by certain ideas of triangularity, which is not that interesting a view. Only if we argue that all desires are triangular, do we say something exciting. Let us keep it all simple and stipulate that Girard presents a theory of mimetic desire saying that all desires in the end are copies of some given models. These models are persons, although in the case of Don Q the models came from literary sources. But this was Girard's initial first example, and in his later writings the sources of desire are persons. Therefore, let us say all desires are copies of other agent's desires. This may create a tricky problem: certain types of agents are sources of desire and others are recipients. I do not want to raise the question of how those authoritative positions are created and maintained. Instead, I suggest that all agents are at the same level: we all copy other people's desires; I copy them, they copy me. If we dismiss this point, we also need to explain where the authorities get their characteristic desires. Whom are they supposed to mimic? Who are the authoritative super-sources

5 Girard, 1965, Ch. 1 “Triangular' Desire.” See also M. Kirwan, Discovering Girard. Lanham: Cowley Publications, 2005, Ch. 1 "Desire is Mimetic." 
and why? Notice that Girard's theory is not new if he speaks of the mimesis of desire simpliciter, which has been known since Antiquity in all forms of hero worship. The Christians speak of imitating Jesus Christ as a special model. If all desires are mimetic, what about Jesus's desires?

Of course one may still ask what happens to unique or idiosyncratic desires. A person desires something new in the sense that the desire is peculiar to him and only to him. It may well happen that other persons possess or have possessed such a desire but our person has no previous experience of it. Her desire is certainly a normal desire but, anyway, exhibits a two-place relation. Should we say that a unique mental state cannot be a desire but something else, like a perversion, whim, quirk, or craze? Of course, if the desire is unique to the subject, it may be such. Logically and analytically much depends on the answer but, for Girard, it does not matter. He says that all desires exhibit a three-place relation, although he cannot really mean it. What he means is that all interesting desires do so. Two-place desires are, therefore, oddities we need not worry about. They may or may not be desires and that is all one can say. When you think of it, it is surprisingly difficult to describe a desire which is totally unique to a given subject in the sense that no one never heard about it, or it is not a combination of some familiar desires. This psychological difficulty speaks for the three-place theory of desire.

\section{Model, Not Desirability}

Now, if we accept the three-place relational theory of desire, what are we speaking about? Notice that desire is usually depicted by means of a two-place relation: I desire X. However, according to Girard, desire entails a three-place relation: I desire $\mathrm{X}$ as $\mathrm{Q}$, that is, as desired by others. But this is not an immediately convincing novelty; I always desire $\mathrm{X}$ as something, namely, as desirable. I cannot desire something that is undesirable or repulsive. For instance, I desire $\mathrm{X}$ as something pleasant, valuable, or rewarding. This theory has one glitch, though. Some objects of desire are intrinsically desirable, for instance, I desire her love or I want a reward. Perhaps I want pleasure. In this case I cannot ask for an explanation of the desirability of love, reward, or pleasure - these objects are intrinsically desirable. If I want ice-cream, you always can ask why, which is an invitation to produce the third element of the desire triangle, that is, the desirability condition. In this case, one may get something like some quick pleasure. I suggest the following solution: suppose $\mathrm{X}$ is an intrinsically desirable object, which is to say it represents a two-place version of the original three-place one. In other words, I want X because of D but now I need not mention D. It 
is redundant. I truncate the original three element desire because the third member is now tautological. Hence, all desires are not explicitly triangular. Of course, the easy way out is to say that, in the case of an intrinsically desirable desire, the third element is there but it need not be explicated. "I want love" is an abbreviation of "I want love (because love is desirable)"; compare, "I want ice-cream because it is sweet (because sweetness is desirable)."

In this perspective we can say, Girard has created another theory of desirability, namely, $\mathrm{X}$ is desirable to me when it is actually desired by others. Therefore, desirability means "actually desired by others." Notice how radical an idea this is: other people do not desire $\mathrm{X}$ as something pleasant, valuable, or rewarding because they inherit their desires from others, or in other words, the only thing I find directly desirable is other subjects' objects of desire, whatever they are. The desirability of X means "desired by others." This entails the fact that no object of desire is desirable as such. For instance, a pleasure that is rejected by all others cannot be desirable. If some subjects desire it, it is desirable. This is to say that we always need three terms to describe a desire: the subject who desires, the object of her desire, and the source of desirability, which now specifies the mimetic option. In this sense mimetic desire constitutes the new normal: if we are normal subjects our desires are copies, or our normal desires are copies, from which it is only a short leap to the idea that the desired $\mathrm{X}$ is a normative entity; that is, I should desire $\mathrm{X}$ because others do so and, hence, $\mathrm{X}$ as a desired object conforms to the new normal. If $I$ fail to desire $X$ and instead desire idiosyncratic Y, I am abnormal, which is something I should avoid. In this way desire tends to create second order normative desires: If I desire X, I also should want to desire $\mathrm{X}$ and so I desire to desire $\mathrm{X}$. I will return to the import of this idea below.

Girard and his followers may also emphasize desire as a three-place relation in a deeper sense. They may argue that I desire $\mathrm{X}$ not only because $\mathrm{X}$ becomes desirable to me via others desiring it but because I copy the desire itself. Notice that desirability does not logically entail actual desiring because desirability is only a necessary but not a sufficient condition of desiring. Many, or most, desirable objects are such that I do not desire them. I simply fail to do so. Do not lust after your neighbor's spouse, however desirable he/she is, is a good idea but it presupposes that some desirable things are not desired. In the same way, I understand that $\mathrm{X}$ is desirable to other people and I may also find $\mathrm{X}$ personally desirable without desiring it, but I cannot desire $\mathrm{X}$ if it is not desirable. Now, Girard seems to say that I actually desire X because others desire $\mathrm{X}$; that is, I desire $\mathrm{X}$ along with the others; this is a theory of desire acquisition that bypasses the problems of desirability altogether, why? The standard theory might be something like this: I find $\mathrm{X}$ desirable, $\mathrm{X}$ is significant to me in 
my present situation, and I hope I may get X from where I am now, so I desire $X$. Perhaps Girard's theory says that I believe X is desired by others, I recognize this, I relate to these people, and I believe I can get X, so I desire X. Notice that I need to restrict the class of people I imitate; it can be called my model class. We can now talk about a mimetic imperative, which triggers off my actual desiring: desire what others desire and never ask why they desire it. This makes desirability conditions vanish. We come close to having a novel push theory of desire. Those do not play with desirability conditions.

Next, Girard's three-place theory of desire radically changes the way we talk about desire. I normally say "I desire X," which now logically entails "We desire X" because my desire of X necessarily is shared with others. However, I never can be sure of other people's desires - I must infer them from their behavior and testimonies, which tend to be incomplete and even misleading sources of information. Therefore, I copy what I believe they desire. Hence, I say something like "I desire $\mathrm{X}$ since, I believe, among other things, that they desire X," which entails "I believe we desire X." Perhaps they do not desire X or they desire $X^{*}$ that is not quite the same as $\mathrm{X}$. Here we find a novel three-place relation, "It appears (1) to me (2) that we desire X (3)." Or even "It appears to me that I should desire X like my sources do," which, for two reasons, does not entail "I desire X." First, strictly speaking, no such thing exists - proposition "I desire X" is empty; as a two place relation it is only a linguistic shortcut. Second, obviously I may resist the force of "should." The third term indicates my leap from a two-place relational expression to a three-place expression, which brings about the additional thought that makes my expression an instance of oratio obliqua. In other words, it is no longer true that I desire X oratio recta or de se. I cannot say "I myself desire X" because now we desire X.

When I say I desire X, I use an ellipsis, which can be true only if it is accepted in the mood of linguistic generosity. This mood comes in two different types: first, in regard to evidence and, second, to abbreviations and shortcuts, that is, ellipsis. We often accept propositions whose evidential support is inadequate when we think, counterfactually, that the full support to it would be easy to find. The proposition may also be so conventional that we accept it regardless of evidential lack, like "Mothers love their children." However, we are now interested in the second type of linguistic generosity, namely, tolerating shortcuts. We do this all the time. When I use a two-place relational expression instead of a three-place one, this is what happens. In most every-day situations I can be generous but situations where I should not may exist as well. Too much generosity is not a virtue because in that case I may miss, so to speak, the true nature of some key facts, events, and attitudes. In Girard's case, it is almost too easy to be generous because three-place relational expressions tend to be 
so clumsy and tedious to use. I then use a simpler expression hoping that my audience understands that I mean something much more complicated. It is indeed difficult to see how to formulate the relevant oratio obliqua expressions. I suggested above something like "I think we desire X," although that does not sound quite right. How should we formulate it in order to express Girard's seminal and celebrated idea correctly?

As we know, Girard's main idea concerns desire acquisition and not desirability, expressed in its core form as follows,

I desire $\mathrm{X}$ because others, whom I mimic, do so.

This causalistic formulation requires a counterfactual background: If others did not desire X, I would not desire X regardless of what it is like. Girard must think that this entails something like a principle of dependence of desire: desire depends of mimesis, or

I would not desire $\mathrm{X}$ or Y, if I did not mimic others,

This entails a set of general conditions that hold of all desire, for instance: I am in a suitable position to mimic others, there is something to mimic, and I have the relevant abilities and prior interests. Then, I mimic others and desire what they desire, understood in terms of the idea that desire always has its object. Mimesis will, therefore, look like a process of object acquisition. If and only if I believe that they desire $\mathrm{X}$, it follows that, granting some relevant background conditions, I also desire $\mathrm{X}$. I desire $\mathrm{X}$ because they do so. If I find $\mathrm{X}$ unsuitable, I may instead desire Y, if I first locate a suitable set of other people desiring Y. Of course, I cannot copy all the desires I happen to observe in my social environment.

Now, what is the correct oratio obliqua formulation of a desire sentence, if Girard is right? One may suggest that the following sentence tells us what desire really is,

(s) I realize that I prima facie should accept X, which my source appears to desire, to be the object that I am to copy in the right socio-mental context and call it oratio recta "I myself desire X" under the principle of linguistic generosity.

It follows that, according to Girard, I no longer desire $\mathrm{X}$ simpliciter but my relevant mental episodes change into something else, like the acceptance of others' desires and their objects plus a normative condition. Of course, we cannot say of others that they desire $\mathrm{X}$, except in terms of the principle of linguistic 
generosity. We can change their desire descriptions into three-place relations. I then imitate desires that are not desires simpliciter but something else understood in terms of (s). We are all in the same boat, so to speak, because we all mimic each other. This should be easy to accept: we cannot create two different classes of desire, those that we copy and those that are results of copying.

Now, we may say that desire is, by definition, something that I accept as the object of my relevant propositional attitude that we usually call desire. Next, we need to eliminate the word "desire" because otherwise our account is circular. We do it by replacing "desire" by its nominal definition, such as a "propositional attitude that entails the direction of fit of the world to the thought"; in other words, in the case of desire, I think of a possible world that should conform to my thought of it. When I want to be rich, I am invited to think of a possible world where I am rich and my actual world should change accordingly. We then get something like this, call it $\left(\mathrm{s}^{\prime}\right)$ :

(s') I myself accept $\mathrm{X}$, which my source appears to desire as $\mathrm{X}$, as the object I am to copy in the right socio-mental context where we all accept $X$ as the object that one should recognize as what we desire, when we face an accessible possible world that is better than the actual world.

Now, sentences (s) and (s') refer to actual episodes of desire: according to (s) and $\left(\mathrm{s}^{\prime}\right)$, I myself actually desire $\mathrm{X}$. This of course requires that the background conditions are right so that $\mathrm{I}$ can move from considering $\mathrm{X}$ in positive light to actually desiring $\mathrm{X}$.

Notice that (s') gives rise to a problem, which is its reference to possible worlds. The mimetic theory does not need it because now desire does not track its satisfaction. But along with it also disappears the direction of fit argument that looks essential to any theory of desire. ${ }^{6}$ We may well argue that this fact refutes Girard, but I will not pursue that line of criticism here. Let me explain: When I copy another subjects' desire X, I need not think that X indicates a better possible world. Neither do I think that that world should conform to what I desire; on the contrary, I feel the normative force of X and thus I copy it. What happens when $\mathrm{X}$ is realized, if it is realized? The world may have not changed into a better one from my personal point of view. I did not desire $\mathrm{X}$ because I wanted a better world; I desired X because this is what the others desire. Actually, it does not matter whether I get the desired object, or not. I need not pay attention to why my sources want $\mathrm{X}$ because it is enough for me that they do so. Hence, mimetic desire is not desire in the normal sense. Here is a simple

6 See Ch. 2 in this book. 
example. I cannot eat ice-cream. It makes me sick. My reference group desires ice-cream and therefore I desire it. I get it but the consequences are bad. I have desired something of which I know it is bad for me, or the object is not desirable for me.

It does not matter why exactly my sources desire $\mathrm{X}$. It follows that it does not make sense to talk about the satisfaction of the desire for $\mathrm{X}$ in connection of mimetic desire. Getting X may not make my world any better. In other words, I did not acquire the X-relevant desire because it promises to make my world better but simply because others desire X. If my better world mattered, it would not exhibit such blind copying, and so it is essential to Girard that the desirability of $\mathrm{X}$ is not mentioned.

We now talk about desire and desiring in a novel sense. Suppose we adopt Girard's triangle, or his three-place theory. I then argue that we also must accept the causal or push idea of mimetic desire. In this case it follows, as I showed above, that Girard sketches an idea of some socio-mental processes that do not generate desires in the standard sense of the term. None of the formulations above really qualifies as an account of desire, as the term is usually understood. Perhaps Girard talks about a causal theory of action where mimesis is the driving force? I see that all people wear blue jeans and so will I do the same. My motivation is mimetic in such a way that it bypasses desire and leads directly to action, that is, to buying and wearing blue jeans. We can then, post hoc, say I desire blue jeans but this is a backward looking explanation meant to convince my audience that I knew what I was doing. In other words, the use of the term "desire" is an ad hoc rationalization in foro externo. Actually, I act because I am causally driven to act, and thus I need to tell about it to others using our common language of desire. Mimesis bypasses desire when it is in an actionist context. We move from imitation to action and afterwards explain it all by means of desire language. If I adopt their desire, I cannot say I de se desire the given object.

\section{Scripted Desires}

Next, let us consider another possible triangular theory of desire inspired by Girard. Objects of desire are socially scripted for their desirability on the social stage and this is to say they are not copies of other persons' desires. I need not mimic others because we all act according to shared scripts. What is important is that we share the socially constructed scripts. ${ }^{7}$ Also, we need to talk about

7 For an another type of approach, see N. Rescher, Unselfishness: The Role of the Vicarious Affects in Moral Philosophy and Social Theory. Pittsburgh: University of Pittsburgh Press, 1975, Ch. 2. 
life on social stage where we play our designated roles. How the scripts are created must be addressed as well. All this comes very close to what Girard says.

Let us first look at the structure and dynamism of individual desires. The main point here is that de dicto desire can be understood as follows: An agent desires de dicto $\mathrm{X}$, which entails that he understands $\mathrm{X}$ in terms of a narrative about X; I call this the narrative account of de dicto desire. Suppose I want X and I say so. This should be followed by a why-question, except in those cases where $\mathrm{X}$ is understood to be prima facie intrinsically desirable. ${ }^{8}$ This is to say one finds $\mathrm{X}$ desirable as such, for instance, when $\mathrm{X}$ is morally valuable or aesthetically pleasing. However, in most cases I must answer a why-question by referring to an explanation of my choice of $\mathrm{X}$ in such terms that brings $\mathrm{X}$ closer to something that is prima facie intrinsically valuable. This question-answer game may contain more than just one move and it also may end up in a position where no common view on the desirability of $\mathrm{X}$ can be found. We are here dealing with subjectively and culturally open ended value judgements, so this is something to be expected. The main point is, however, that such a dialectics generates and utilizes narratives that constitute socially understandable de dicto desirability conditions.

An example: I want to be a good father. It is hardly plausible to ask why but necessary to ask what I mean, or what I think a good father is like and what one needs to do in order to become a good father. I say I want to be a stern and strict father to my children, and then a why-question is in place. The reason is obvious: stern and strict are evaluations that normally do not carry a positive tone of value in today's normal context. I then explain that I want my children, girls included, to be ready for the armed services where they will be warriors. Many of us might disagree on the desirability of such an object and hence ask for additional explanations. When these arrive the narrative gets richer and, hopefully, more convincing in terms of its desirability ascriptions. Of course such an account of the creation of de dicto desire and its narrative basis may not require actual social exchange; I will relate it to myself in my own terms when I reflect on my desires and the values behind them - everyone can do it. We tend not to do it when the desire in question feels uncontroversial or conventional. When the desire is weird and normatively challenging, my relevant soliloquy may show signs of self-deception.

Let us then look at what I called social scripts of desire. By referring to them one can say desires are socially constituted without saying that they are copies

8 We also use desire language to give motivational explanations, for instance, "Why did you steal the money?" Answer: "I wanted to buy something." Also, we can issue hidden commands like "I want you to go and get it." 
of other people's desires. Let us take a closer look into the notion of a script. Scripts are socially recognized and shared ideas of what is and can be desirable. Such scripts are more or less widely shared, or more or less partisan. The latter category is interesting because it creates and follows certain social divisions that can be and will become problematic at many different levels and ways. However, it is hardly an exaggeration to say that when we desire we desire according to a shared social script, or that our desires are scripted. Of course, we have a large number of scripts available to us, some I may not understand, some I find repulsive, and some I find understandable and attractive in the sense that they actually exert a pull towards them. A simple case is like this: a given script is normally accepted by my own social reference group and therefore I find it attractive.

Let me give more examples: you might refuse to understand some religiously motivated ascetic regimes. Many people find sadomasochistic sex-plays difficult to accept as reasonable or attractive - they cannot imagine they would feel the pull of them. One may find social generosity in terms of voluntary work and financial donations valuable objects but nevertheless feel no pull. Here one recognizes the script without personally adopting it. Finally, one may find learning foreign languages a valuable object as a script, recognize it, and also adopt it. Learning a foreign language may be an actionist or non-actionist desire, depending on how one reads the term "learn." It may imply one's own activity and action or it may not. I may hope to learn a language by some passive adoption method, especially if the targeted competence level is low. Be this how it may, the pull depends on the acceptance of the given script in my social reference group.

The scripts are socially available to guide individual desire selection and formation processes, or in their extended form, to instruct one of what there is to be desired, what to expect of one's desires, and what to be aware of in terms of negative consequences. Scripts can be divisive and controversial: my idea of fun may include criminal and violent desires for which a full set of scripts are available via competent model agents, for instance in prisons. Notice that one may adopt a criminal script even if my actual social surroundings are law abiding. This is because the person can imagine an accessible possible world in which such scripts are in normal use. Later on, she may find herself in a situation in which the relevant social reference group is a real one; again, prison is a relevant example. Therefore, I only require the known social existence of the script that explains its pull. But it is a prima facie plausible to argue, I think, that a person gravitates towards the actual social groups that support and develop the scripts that the person finds attractive. She finds such groups desirable. 
By recognizing a script one starts on a slippery slope towards adopting it and the relevant social identity, which is sometimes cursed sometimes admirable. Notice that many types of scripts are mutually exclusive, or they imply mutually incompatible social identities; a person with multiple identities may exist, or course, like the mythical Mafioso who is at work a cruel killer and at home a tender father, thus realizing the respective, mutually incompatible scripts of his two roles side by side. The explanation of this is simple: the scripts need not be universalizable. Anyway, any unscripted goals imply Otherness due to unrecognizable desires that lead to socially impossible and false identities. We may call them perverted. We may then fail to know what to say about your alleged desires. The key principle is, if you personally desire something $\mathrm{X}$ a relevant script also exists.

Scripted desires are located on social platforms, or whatever you may call them, for instance the stage and the backroom..$^{9}$ On the stage you need to display desires that suit your present role and social identity, support them, and continue them as expected by those who know, recognize, and adopt related scripts and roles. If there is a backroom, which I doubt, we are free to adopt different desires without role related constraints - there we are free. But, as I said, I doubt the existence of such private social spaces. It seems that any backroom behavior is scripted as well, or in other words, it is just another type of social stage. For instance, locker rooms are far from the arenas where one performs but they are not backrooms. We are in this sense totally and unavoidable social creatures who are bound together by our scripted desires on the social stages where we play our designated roles. However, if we want we can draw a distinction between the stage and the backroom, in the following way. On the stage we utilize the scripts adopted from our actual social reference group. We express ourselves as we should. In the backroom we may desire whatever pleases us, in the sense that there the scripts are based on the desires of alternate social groups. These must exist but not in the actual world where the person happens to live. He may adopt all kinds of imaginary models in the sense that he imagines his membership in some existing reference groups. In other words, he imagines a possible world where these groups are his social reference groups. The backroom is where the person is free in this limited sense. It is not a place where he can desire without any scripts. It is not a madhouse.

I cannot develop this special theme any further here. I only hope I have made it clear how the argument proceeds: our desires are socially scripted

9 E. Goffman, The Presentation of Self in Everyday Life. New York: Anchor, 1959, Ch. 3 "Regions and Region Behavior." Together with Veblen, Goffman explains much of the mimetic life of social beings. 
cultural entities without any clear-cut formation process or procedure; the scripts are so basic to our social life that they cannot be explained in any simple terms. They are there and they have always been there as dynamic and malleable as ever. We live by them. Moreover, all this happens on the social stage, which is partially defined and constituted through the scripts that we play over there. The next step, would we like to continue on this track, is to consider the relationship between the stage and social roles, but obviously this would take us too far from my intended Girard interpretation and criticism.

The next question is, then, what is the relationship between our personal narratives of de dicto desire and social scripts. These considerations take us a long way towards a definite criticism of Girard's idea of mimesis. What looks like mimesis can be explained as follows in a way that exhibits at least some analytical clarity. A script is a model for personalized narratives of desire or, in other words, we formulate narratives according to a given script, which guarantees them at least some social communicability, comprehension, and acceptance. This would not happen without scripts because I might form a narrative of my de dicto desire that I could not communicate, perhaps not even to myself. This is to say I cannot tell what I desire and consequently I must say I do not desire - my attempt to generate a desire fails both in foro interno and externo. I may feel an urge in a certain direction or in a certain field of considerations but I cannot tell what it is. Therefore, I need a script according to which I formulate the narrative for my prospective desire and the desirability of its object. An example: all people eat ice cream in summertime in the park, when the sun is shining and birds are singing. This is a well-known script for that special stage performance that most of us willingly partake in our summer fun roles. We then formulate our narratives accordingly so that we may answer the questions about our willingness to eat ice cream then and there. In some cases, the script is so obvious and recognizable that I do not even notice its influence on my desire - it comes forth as if automatically.

Here we need to consider two different types of cases. First, I de dicto desire an object whose full narrative is such that it provides both some clarification of the meaning of the object and an explanation of its intrinsic desirability. Suppose a case where it is not clear what script I have adopted and, therefore, I have to review and question the narrative in order to get answers to the questions concerning the missing features of the object, both normative and analytical. I want to marry Mary. We all know several different suitable narratives: my parents want it and I want to be a good son, I want her money, I lust her, I love her, or I cannot get anybody else. I need to tell a full narrative concerning the desire and its object before you or I know what is going on. Second, we have 
many cases that are clear from the outset, so I need not formulate a narrative instead I adopt the script as such and let it replace my prospective narrative.

Another type of case exists as well, namely a case in which the obviousness of the narrative conclusion is not based on the prima facie intrinsic desirability of the object of desire, like in the good father case. In the ice cream case we cannot say that ice cream in the park is somehow an intrinsically valuable object of desire - it is not. Instead we say that its script is so well-known, widely spread, and easily acceptable that we do not need to explain it any further. If you do not know this kind of action on the social stage, how could I explain it to you? No one should come and ask why I eat ice cream in the park or what it means to do so. If I want to learn Medieval Latin I must be ready to answer questions unlike if I want to learn English. The only possible questions in the latter case are when, where, and how, all of which in a minimal sense clarify my narrative. However, its desirability is obvious and the meaning of the relevant desire clear. As I have argued, I do not copy other people's desires, nor do they copy mine; instead, we all act on publicly known social scripts according to which we formulate our narrative de dicto desires. Scripts and narratives are thus logically connected: there is no desire without its narrative and no narrative without its script; this is the law of the land of desire so that only madness may live beyond its borders.

What then is wrong with Girard's mimetic theory? Better theories can be formulated but this is not the same as saying the mimetic theory fails. To put it briefly, any account of the mimetic process of desire acquisition is a simplification of the script/narrative dialectics. Mimesis may work as a heuristic tool, or as an explanans for some more interesting phenomena, such as religious remedies for persistent social violence - as Girard himself does. However, if desire is the explanandum the mimetic theory does not do much work. Nevertheless, it is obviously true that we copy each other's behavior, emotional reactions, values, desires, and many other things. The question then is, what is behind it. To copy is to affirm and contribute to the existing script that allows one to desire according to one's own desire narrative.

\section{Desires, Not My Own}

Let us suppose that the Girard's mimetic theory of desire is valid. Then it is fit to explain a peculiar phenomenon, namely, the anxiety that is so often associated with desires for instance in such fields as sex and religion..$^{10}$ The main

10 See M. Foucault, Abnormal. Tr. G. Burgchell. London: Verso, 2003, Ch. 8. 
point is that copied desires are not the agent's own as I already explained; they still belong to others. One borrows them or they are mere reflections in a mirror that is the agent. If I copy my desires I may wonder what I have copied, what those desires are, and, most basically, what these desires mean to me versus the source of them. Girard says I envy and even hate the source because the source is somehow prior and supreme in relation to me."

How can I make desires my own, or how to identify with them? In this sense, the copied desires look like alien entities and unmanageable intrusions by the Other. How could this fail to trouble me, especially if I realize that all my desires are copies or reflections of the Other? I feel as if I had no identity nor self. My desires are no longer my own and yet I am supposed to express myself - my unique and invaluable selfhood - in terms of them; the desires I have, must be my own. Such psychological dissonance must trouble me no end and lead to nameless and objectless, free floating anxiety. ${ }^{12}$ I am not what I am supposed to be. Girard writes, "The subject is convinced that the model considers himself too superior to accept him as a disciple." This provides one possible explanation of the gap between the agent and her model/source: a model is always better and preferable to a copy so that the two players' relations are characterized by their mutual alienation. Notice, however, the following facts. All desires are copies, therefore no model enjoys original desires. It follows that a model may consider herself superior to me but because her desires are copies as well, she must feel the relevant and related negative effects, too. Moreover, because she copies she must copy me, which is to say I can feel superior to her. The result is that no privileged model agents exist; on the contrary, we all copy each other and thus we also hate each other, as if democratically.

An obvious solution is identification, or a mental process by means of which I somehow make those mimetic desires my own. Alas, we know we tend not to succeed because our desire induced anxiety levels in fact remain high and thus we quarrel and fight, just as Girard says. This indicates a lack of a process, method, and filter that systematically reject such desires that are bad, meaningless, or unsuitable for me. As an old man, I should not copy the desires of young men. Moreover, when I am already equipped with a characteristic set of desires, I only copy such desires that fit the already established desires of mine, or if they do not fit directly, at least they tend to make my original set of desires

\footnotetext{
11 Girard, 1965, pp. 11, 41.

12 See R.A. Wicklund and J.W. Brehm, Perspectives on Cognitive Dissonance. Hillsdale, N.J.: Lawrence Erlbaum, 2013, p. 1. Cognitive dissonance implies a desire that the agent wants to reduce or eliminate but has trouble of doing so. This brings about anxiety, see Ch. 4 in this volume.
} 
somehow better - which presupposes the existence and use of some criteria of betterment. This shows that Girard's mimetic theory of desire acquisition requires some rather complicated psychological theorizing if one wants to keep it going. Anyway, I want to concentrate on the problem of alien desires, the desires of the Other, or copied desires, those that are not my own and remain so. The problem is this: mimesis as the source of desire does not explain the right thing; the reason for this being that no copied desires are mine. In many cases, when I copy a desire I do not know what to do with it, so to speak. What should I copy when the set of sources for copying is so immense, even when I restrict it to those of my social reference group? What we need is a method or a process that allows me to find and own my prospective desires. Then the two main questions are, what are the desires I identify with and how do I do it?

Think of Don Quixote, Girard's original hero and inspiration. The old man, Mr. Alonso Quixano of La Mancha, reads too many chivalric romances and because of them wants to be a wandering knight himself. ${ }^{13} \mathrm{He}$ is going to perform heroic deeds all over Spain. Girard starts his own, rather quixotic project together with the knight, but what that starting point is, is not at all easy to say. Mr. Quixano reads historic fiction and finds some narratives of desire there that he promptly copies and puts into action in his own inimitable manner. He is mimicking some outlandish narratives about heroes whose desires Mr. Quixano takes to be invaluable in the sense of being sublime and noble, and as such intrinsically desirable. This presupposes his own values point of view that allows him to say the chivalric desires are admirable in their nobility and the corresponding actions heroic and as such worth trying. However, the narrator says the old man goes crazy in the sense that he is incapable of understanding properly what he reads: "In short, his wits being quite gone, he hit upon the strangest notion that every madman in this world hit upon."14 In this way, he identifies with the knights of these chivalric romances because he is mad, or he goes mad by reading them. In both cases the idea is that no one in his normal state of mind would do so. Obviously we need better examples of the genesis of mimetic desire.

Perhaps we should read Don Quixote's madness as symptomatic of the discrepancy between his normal desires and his novel, simulated desires. Indeed, the material he copies and mimics is so outlandish and improbable that he

13 P. Tabori, The Natural History of Stupidity. New York: Barnes \& Noble, 1993, Chs. 3 and 9. Tabori describes very well the world where Don Quixote wanted to live. It was a mad world and that is why he was mad. It is mad to want to imitate madness; his is mimetic madness.

Don Quixote, Ch. 1. Tr.J. Ormsby (http://www.gutenberg.org/files/5921/5921-h/5921-h.htm). 
must be crazy to identify with it. Hence, it is not really the case that the read material, chivalric romances, make him mad but that he is mad to identify with them in the first place. The author, Cervantes, certainly plays nicely with this crucial ambiguity in the beginning of the novel. We also can say the old gentleman's madness is a metaphoric expression of the experienced anxiety when one lives by so many desires that are not one's own and make life a mere show of impersonation on a misconstrued social stage. His desires are, therefore, mere caricatures of what they might and should have been, that is, his own. It is undoubtedly a different thing to desire de dicto in the mood of oratio recta or oratio obliqua. I may desire X or apparently and allegedly desire $\mathrm{X}$, which indicates a major difference between the relevant attitudes towards the respective desires. In the first case you can honestly stand behind your desire ascriptions and their communication knowing it is your own desire based on your unique role on the social stage. In the second case the same can be said only if you personally recognize certain desires and they, as copies, actually fit their models, so that your own already existing desires support the new items. However, all this presupposes either that some of your existing desires are originally your own, that is, they are not copies, or that an independent identification procedure for occurring desires exists and works. If all desires are copies, you can never make new desires your own.

In any case, you can avoid the problem of alien desires that tend to cause anxiety or presuppose a bout of madness. We need something that helps us deal with alien desires. It seems hard to accept the claim that you could live on by such alien desires when all of your desires are equally alien. If it is indeed the case that all our desires are copies of the desires of the Other, we must have developed some mechanism of identification of what is our own, or otherwise we were still grappling with our endless desire based anxieties. Perhaps we to some extent do so, as we can see when we think of how anxious so many of our desires still make us. We are driven to copy, act out, and live through so many desires that in the end are alien to us and whose fruit is denied from us.

Let me suggest the following: Many desires are forbidden on the social stage, for instance, certain sexual desires, all blatant expressions of egoism, many religiously suspicious ideas, etc. In some Muslim countries blasphemy is punishable by death via sentencing that can be official as well as based on vigilantism. Here the idea is that desires become visible in action and speech. Now, desires and their outward expressions can be dangerous, so the first step is to forbid them and educate people to avoid them; then, bad desires are simply not available for copying. Once we know this, it is much easier to identify with those desires that are still available. Various kinds of sanctioning systems control what one can and should copy, like do not copy female desires if you are male, and 
so on. It is therefore true that the life on the social stage is carefully regimented in terms of what desires are available to whom to copy and all this tends to be sanctioned. Yet, such procedures can never overcome the final and ultimate problem, namely, the desires that I am allowed to mimic are not my own desires and they never will be.

The only way to overcome this fundamental problem is to say that, if I may hope to be a happy and fulfilled person, I copy those desires the source of which is such that I can identify with it. In this way, I identify with model persons and then their desires, which I copy, if they are such that I can adopt them as my own. I need to recognize my models and find them acceptable, and only after that can I safely adopt some novel desires. In this case, I doubt if one still can maintain that we copy all our desires. If I identify with a desire model $\mathrm{A}$ and because of that adopt desire $\mathrm{X}$, am I still copying $\mathrm{X}$ from $\mathrm{A}$ ? I do not think so. To copy entails another kind of relation to the source, a relation that is in the sense external and not internal. This is the difference between internal and external relations: My desire for X is internal if and only if I am not what I am without my desire for X. In this sense, my desire for X constitutes me as a person; otherwise the relation is external. Perhaps we can say that many desires are external but those that matter must be internal. Of course, such minor desires may well be copied; it does not matter. The major desires must be internal or the person is in major trouble; one must not copy such desires even the scripted desires may prove to be problematic, if we hope to be unique individual persons.

Here a new problem emerges. How do I mimic desires? Such desires must be available to be mimicked, which they normally may not be. On the contrary, desires are mental entities and episodes, of which the agent and only the agent herself may be aware of. Desires are displayed on the social stage, that much is certain, but how does that happen? The common assumption is that desires become visible in bodily actions and verbal behavior, which may be true to a certain extent. However, we should not make assumptions to the effect that desires are visible on the social stage because they are motives for action - they are not motives for action. Sometimes desires are of the actionist type in the sense that their formulation refers to action, but this is not always the case. Many desires are of the non-actionist or idle type. If desires are not motives and they are idle, how do you copy them? The only possibility is through verbal behavior or written accounts; Don Quixote reads books and many of us listen to verbal reports of others. This leads to the following situation: many desires are hidden, they are fictionalized, or they are made known via inherently unreliable and often untrustworthy testimonies. Desires are not as straightforward to mimic as Girard may make us believe. What we get is a kind of double oratio 
obliqua: I copy something like "He says he desires X" or "She behaves as if she wanted Y" and so the result is not something like "I copied X" and therefore "I accept that I now must desire X" but

I copy (I must desire what (he says he desires)), that is, $\mathrm{X}$

or,

I accept I must desire $\mathrm{X}$ that is what he seems to desire on the basis of his actions on the social stage.

To me, such a construction seems dubious. If taken seriously, the mimetic theory looks intractable. Obviously, we are able to desire $\mathrm{X}$ de dicto and oratio recta and thus Girard's theory of desire acquisition is too complicated to be valid, even if it initially looks so simple and appealing. 